\title{
MUDANÇAS NO MERCADO DE SERVIÇOS DOMÉSTICOS: UMA ANÁLISE DA EVOLUÇÃO DOS SALÁRIOS NO PERÍODO 2006-2011
}

\author{
KêNia BarReiro de Souza * \\ Edson Paulo Domingues ${ }^{\dagger}$
}

\begin{abstract}
Resumo
Os trabalhadores domésticos estão entre as categorias mais beneficiadas com os aumentos reais de renda no Brasil, embora sua remuneração média continue muito distante do restante da economia. Nesse contexto, este artigo buscou investigar as consequências econômicas das mudanças no mercado de serviços domésticos, utilizando um modelo de equilíbrio geral computável (BRIDGE). Em termos gerais, os resultados mostram que $0,58 \%$ do crescimento econômico acumulado entre 2006 e 2011 (ou cerca de $\mathrm{R} \$ 19$ bilhões de reais) podem ser atribuídos ao aumento da renda do trabalho doméstico e ao correspondente crescimento nos custos desses serviços.
\end{abstract}

Palavras-chave: Trabalho doméstico; Salários; Equilíbrio geral computável.

\begin{abstract}
Domestic workers are among the most benefited groups from the increases in real income in Brazil although the average earnings are still far from the rest of the economy. In this context, this paper investigates the economic consequences of changes in the market for domestic services, using a computable general equilibrium model (BRIDGE). Overall, the findings shows that $0.58 \%$ (or about $\mathrm{R} \$ 19$ billion Reais) of cumulative economic growth between 2006 and 2011, can be attributed to domestic labor income increases and the corresponding growth in the costs of these services.
\end{abstract}

Keywords: Domestic work; Wages; Computable general equilibrium. JEL classification: J31, I31, C68.

DOI: http ://dx.doi .org/10.1590/1413-8050/ea454

\footnotetext{
*CEDEPLAR/UFMG. E-mail: keniabs@cedeplar.ufmg.br

† Bolsista de Produtividade em Pesquisa do Conselho Nacional de Desenvolvimento Científico e Tecnológico (CNPq) e do Programa Pesquisador Mineiro da Fundação de Amparo à Pesquisa do Estado de Minas Gerais (FAPEMIG).CEDEPLAR/UFMG. E-mail: epdomin@cedeplar.ufmg.br
} 


\section{Introdução}

O trabalho doméstico compreende uma série de atividades, como limpeza; arrumação; cozinha; cuidados com o vestuário; cuidados com crianças, idosos, pessoas com deficiência, animais, entre outras. Embora podendo desempenhar atividades distintas, duas características são comuns a esses trabalhadores: o trabalho é remunerado, e realizado em um domicílio que não o do próprio trabalhador (Organização Internacional do Trabalho 2011a,b).

Por essas e outras características socioeconômicas, o grupo de trabalhadores domésticos remunerados possui uma série de peculiaridades, entre as quais se destacam: i) predominam trabalhadoras do sexo feminino; ii) são pagos baixos salários; iii) o empregador é uma pessoa física; iv) a legislação não acompanha a Consolidação das Leis do Trabalho (CLT), sendo inclusive colocada como uma exceção aos direitos trabalhistas pela própria Constituição Federal - CF; e v) há um alto índice de informalidade; (Organização Internacional do Trabalho 2011c, IBGE 2010).

O serviço doméstico remunerado ocupa grande parte da mão de obra feminina, pois, segundo Melo (1998), tais funções são culturalmente consideradas o lugar da mulher. Ao mesmo tempo, a baixa qualificação exigida gera uma alternativa para trabalhadoras de baixa escolaridade e sem treinamento, que se submetem a baixos salários e a um alto nível de informalidade (Melo 1998, Theodoro \& Scorzafave 2011).

Segundo a Organização Internacional do Trabalho (Organização Internacional do Trabalho 2011c), em geral, a remuneração média do trabalhador doméstico é menor do que a metade da média geral de salários, chegando a menos de $20 \%$ dos rendimentos médios para alguns países. No entanto, mesmo com o elevado índice de informalidade, o salário mínimo tende a ser tomado como referência, e funciona como um elemento de proteção e desenvolvimento social (Organização Internacional do Trabalho 2011c, Theodoro \& Scorzafave 2011).

Os baixos salários do trabalho doméstico são em parte explicados pela percepção de que são improdutivos, por não gerarem diretamente ganhos para o empregador. No entanto, seu valor econômico e social não é suficientemente considerado, na medida em que: i) o trabalho doméstico gera efeitos diretos sobre a segurança, organização e bem-estar dos membros da família; ii) aumenta a possibilidade de inserção no mercado de trabalho dos membros da família; e iii) estimula o consumo, gerando renda e assim contribuindo para o crescimento econômico (Organização Internacional do Trabalho 2011c).

Não obstante, a falta de valorização do trabalho doméstico se reflete na legislação, que não inclui o trabalhador doméstico entre as ocupações regidas pela CLT. Tal fato também é consequência do caráter peculiar da prestação de serviços à domicílio e impõe duas dificuldades, reduz as possibilidades de fiscalização no que tange a contratação e jornada, e o efeito da ação sindical (Departamento Intersindical de Estatística e Estudos Econômicos 2006, Organização Internacional do Trabalho 2011c).

No Brasil, apenas em 1972 por meio da Lei 5.859, a profissão de empregado doméstico foi reconhecida e regulamentada, estendendo parte da legislação a esses trabalhadores. Mesmo com a obrigatoriedade legal de formalização, o número de trabalhadores com carteira assinada é baixo, ${ }^{1}$ refletindo a

\footnotetext{
${ }^{1}$ Entre 2005 e 2011, a média de trabalhadores domésticos com carteira assinada passou de
} 
falta de fiscalização e de incentivos à formalização. Esse debate foi retomado em 2013, com a Proposta de Emenda à Constituição (PEC) $n^{\circ} 478 / 2010$, que revoga o parágrafo único do art. $7^{\circ} \mathrm{da} \mathrm{CF}$, estabelecendo igualdade de direitos a todos os trabalhadores rurais e urbanos, inclusive trabalhadores domésticos.

No entanto, mesmo com tantos avanços no que tange a proteção desses trabalhadores, a informalidade e os baixos salários continuam marcantes, e uma das questões recorrentes no debate da formalização é o aumento no custo de contratação de serviços domésticos, que poderia levar a uma redução na demanda, reduzindo as oportunidades de emprego para trabalhadores dessa categoria. Conforme enfatiza Mattos (2009), a imposição de encargos adicionais impacta diretamente na decisão de contratação de um trabalhador doméstico, criando ao mesmo tempo um benefício àqueles que permanecem contratados, e uma redução na absorção daqueles que estão à procura de emprego.

No Brasil, a renda dos trabalhadores domésticos tem crescido acima da média da economia, ao mesmo tempo, em que o número de trabalhadores contratados pouco se alterou, indicando que a demanda permaneceu elevada o suficiente para que não fossem perdidos postos no mercado de trabalho, conforme pode ser observado nos dados da Pesquisa Mensal do Emprego (PME). A Figura 3 mostra a evolução dos salários nominais de trabalhadores domésticos ${ }^{2}$ e outros trabalhadores, entre 2005 e 2011, bem como o valor do salário mínimo nesse período.

Conforme pode ser observado, a situação dos trabalhadores domésticos no Brasil se enquadra nas características ressaltadas pela Organização Internacional do Trabalho (2011c), ou seja, a renda média fica abaixo da renda dos demais trabalhadores e acompanha as mudanças no salário mínimo. Não obstante, entre 2005 e 2011, a renda média do trabalhador doméstico apresentou um crescimento nominal de $86,56 \%,{ }^{3}$ enquanto para os demais trabalhadores, o crescimento foi de $64,01 \%$, o equivalente a aumento médio anual de $10,95 \mathrm{e}$ $8,89 \%$, respectivamente.

Apesar do aumento nos salários pagos aos trabalhadores domésticos, o número de trabalhadores pouco se alterou durante o período, passando de 1.613 .510 em 2005 para 1.548 .372 em 2011, o que equivale a uma redução de $4,04 \%$ em seis anos. No entanto, essa redução combinada ao aumento no número total de trabalhadores ocupados reduziu a participação do trabalho doméstico de 8,47 para $6,98 \%$.

Essas mudanças refletem não apenas uma consequência da elevação no custo do trabalho doméstico, como também o aumento da formalização e a ampliação das oportunidades de trabalho em outros ramos, reduzindo o número de pessoas disposta a atuar em serviços domésticos e aumentando o poder de barganha dos trabalhadores que permanecem no setor (Martins 2012).

Neste sentido, o presente artigo buscou estimar os impactos do aumento dos salários pagos aos trabalhadores domésticos, por meio de simulações com um modelo de equilíbrio geral computável (EGC). Os resultados sobre as va-

35,64 para 38,68\%, segundo dados da PME - Pesquisa Mensal do Emprego - IBGE (2012c).

${ }^{2}$ No caso da PME foi utilizado todo o grupo de trabalhadores domésticos, pois não é possível chegar ao nível de desagregação obtido na POF. No entanto, como os serviços domésticos descritos na Tabela 1 correspondem a mais de $90 \%$ do total de serviços domésticos não há prejuízo para a simulação realizada.

${ }^{3}$ Considerando a inflação acumulada no período de 41,87\%, segundo o IPCA (IBGE 2012c), os trabalhadores domésticos obtiveram um ganho real de cerca de $44,70 \%$, contra $22,14 \%$ dos demais trabalhadores. 


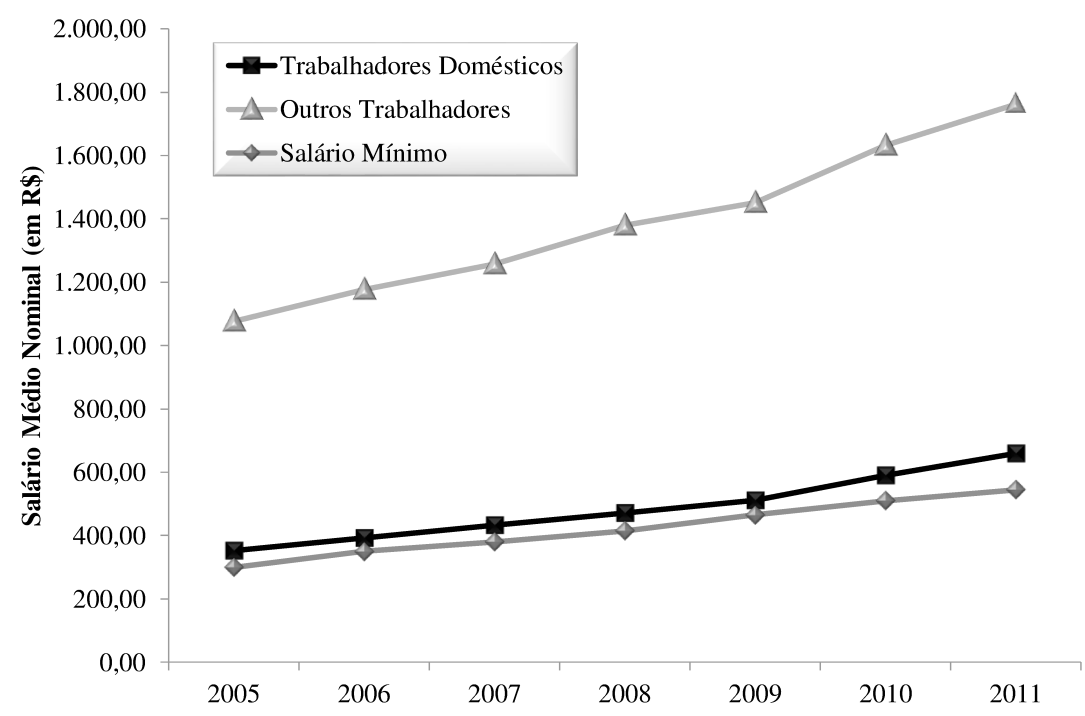

Fonte: Elaboração própria a partir de dados da PME (IBGE 2012b).

Figura 1: Rendimento médio nominal de Trabalhadores Domésticos e Outros em dezembro, e salário mínimo entre 2005 e 2006.

riáveis macroeconômicas e setoriais serão traçados a partir de dois efeitos diretos: i) a elevação no preço do trabalho doméstico e ii) os ganhos de renda dos trabalhadores domésticos.

O trabalho está organizado da seguinte forma: i) a seção 2 detalha a metodologia proposta com a adaptação do modelo de equilíbrio geral para incorporar as mudanças no mercado de trabalhadores domésticos, bem como a estratégia analítica utilizada para as simulações; ii) os resultados são apresentados na seção 3 e iii) por fim, são tecidas as considerações finais na seção 4.

\section{Metodologia}

O modelo de equilíbrio geral computável (EGC) utilizado neste trabalho é denominado BRIDGE (Brazilian Recursive Dynamic General Equilibrium Model). ${ }^{4}$ O BRIDGE foi desenvolvido a partir da estrutura teórica do modelo ORANI (Dixon et al. 1982) e ORANIG (Horridge 2006), incorporando elementos de dinâmica recursiva. Tais elementos são essenciais principalmente no que diz respeito às simulações relacionadas ao estoque de capital (que se acumula ao longo do tempo), ou ao mercado de trabalho (que apresenta certa inércia no ajustamento dos salários e do emprego), como será o caso no presente artigo. ${ }^{5}$

\footnotetext{
${ }^{4} \mathrm{O}$ desenvolvimento do modelo é parte das atividades do Núcleo de Estudos em Modelagem Econômica Aplicada (NEMEA) do CEDEPLAR/UFMG. O grupo conta com a participação de professores e alunos da pós-graduaçâo no CEDEPLAR, sob coordenação do Prof. Dr. Edson Paulo Domingues.

${ }^{5}$ Modelos EGC com dinâmica recursiva não são novos na literatura brasileira. Ver, por exemplo, Domingues et al. (2010), Hasegawa (2003), Haddad \& Domingues (2001) e Fochezatto \& Souza (2000).
} 
O modelo BRIDGE foi configurado para o ano de 2005, de acordo com a classificação setorial e de produtos da matriz insumo-produto do IBGE: 60 setores, 116 produtos, cinco componentes da demanda final (consumo das famílias, consumo do governo, investimento, exportações e estoques), dois elementos de fatores primários (capital e trabalho), dois setores de margens (comércio e transportes), importações por produto para cada um dos 60 setores e cinco componentes da demanda final, um agregado de impostos indiretos e um agregado de impostos sobre a produção.

A especificação teórica do modelo segue o padrão em modelos EGC nacionais, e está representada esquematicamente na Figura 2. Os setores produtivos minimizam custos de produção sujeitos a uma tecnologia de retornos constantes de escala, em que a combinação de insumos intermediários e fator primário (agregado) é determinada por coeficientes fixos (Leontief). Na composição dos insumos há substituição via preços entre produto doméstico e importado, por meio de funções de elasticidade de substituição constante (CES). Na composição do fator primário também há substituição via preço entre capital e trabalho por funções CES. Embora todos os setores apresentem a mesma especificação teórica, os efeitos de substituição via preços, diferenciam-se de acordo com a composição doméstico/importado dos insumos utilizados.

A demanda das famílias (composta por 10 famílias representativas, classificadas por decil de renda) é especificada a partir de funções de utilidade nãohomotéticas Stone-Geary (Peter et al. 1996), dividindo o consumo dos bens e serviços em parcelas de "luxo" e "subsistência", de tal forma, que uma parcela fixa do gasto é reservado ao consumo de subsistência e a parcela residual em "gastos de luxo", o que permite que modificações na renda causem modificações diferenciadas no consumo dos produtos, daí seu caráter não-homotético. Ao mesmo tempo, a composição entre domésticos e importados, é estabelecida por meio de funções de elasticidade de substituição constante (CES).

As exportações setoriais respondem a curvas de demanda negativamente associadas aos custos domésticos de produção e positivamente afetadas pela expansão exógena da renda internacional, adotando-se a hipótese de país pequeno no comércio internacional. O consumo do governo é tipicamente exógeno, podendo estar associado ou não ao consumo das famílias ou à arrecadação de impostos. Os estoques se acumulam de acordo com a variação da produção.

As alterações no bem-estar foram mensuradas em termos monetários, baseadas em duas medidas de variação da renda: compensadora e equivalente. A partir de uma mudança nos preços, a variação compensadora (VC), mensura a compensação monetária necessária — dada a variação dos preços - para que o agente (neste caso, cada uma das dez famílias representativas) mantenha o mesmo nível de utilidade inicial. Em outras palavras, é o montante necessário para que o consumidor retorne a sua curva de indiferença original. A segunda medida, a variação equivalente (VE) mede a quantidade máxima de renda que o consumidor estaria disposto a pagar para evitar a variação de preço e continuar consumindo sua cesta original. Ou seja, mensura o montante monetário que seria retirado do consumidor antes das mudanças nos preços para deixálo tão bem quanto estaria após a alteração de preço (Varian 1992).

A Tabela 1 fornece uma versão estilizada das principais equações do Bridge. O grupo (1) representa a composição dos produtos e dos insumos das indústrias. Cada indústria $i$ pode produzir diversos bens $c$ utilizando insumos domésticos e/ou importados, bem como fatores primários compostos (trabalho 


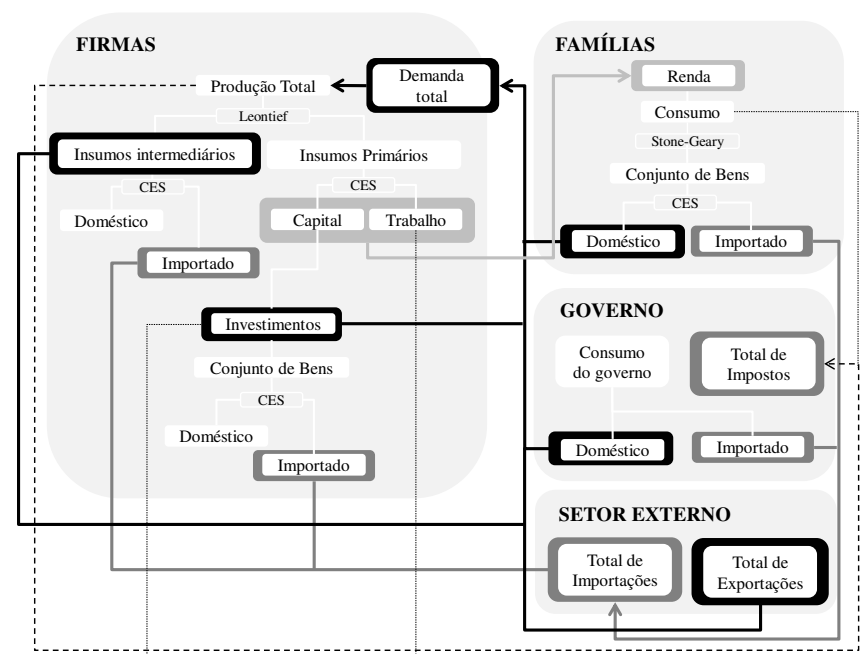

Fonte: Elaboração própria.

Figura 2: Representação esquemática da Estrutura do modelo de EGC.

$L$ capital $K)$. Em (2), a produção de cada indústria $i$ é uma função dos preços $\left(P_{1}\right)$ das commodities domésticas e do nível de atividade $(X 1 T O T(i))$.

A produção total por commodity $(X 0 C O M(c))$ é a soma da produção de todas as indústrias, conforme representado na equação 2. Assumindo retornos constantes de escala na função de produção, um aumento em X1TOT(i) permite a indústria $i$ produzir proporcionalmente mais de todas as commodities. Desta forma, à medida que o nível de atividade aumenta a demanda por fatores primários e insumos intermediários no setor também se eleva na mesma proporção. Consequentemente, a demanda por insumos $(X 1(c, s, i))$ e fatores primários $(L(i)$ e $K(i))$ depende de X1TOT(i). A demanda por insumos intermediários (equação (2)) e fatores primários (equações 2 e 2) é também uma função de variáveis de mudanças tecnológicas $\left(A_{1}, A(i)_{P F}, A(i)_{L}, A(i)_{K}\right)$ em seus respectivos preços $\left(P_{\text {dom }}(c), P_{i m p}(c), W, Q(i)\right)$. Mudanças nos preços relativos dos fatores primários e dos insumos levam a uma substituição em direção aos fatores mais baratos (pressuposto de minimização de custos) formalizado em uma função do tipo CES.

O segundo grupo apresenta as funções de criação de capital. Os insumos usados (equação 2) também estão sujeitos ao problema de minimização de custos, no caso, dos investidores. Portanto, a demanda por insumos da commodity $c$ de origem $s$ para a criação de capital é função da quantidade de capital criado $(X 2 T O T(i))$ na indústria $i$, dos preços do insumo doméstico e importado e de mudanças tecnológicas na utilização de insumos para investimento $\left(A_{2}\right)$. Estes dois últimos fatores também determinam o preço efetivo da unidade de capital adicionada $(P I(i))$, cujo valor é tratado como o preço que uma unidade pode ser vendida, ou preço do ativo, conforme definido na equação 2 .

O terceiro grupo descreve a demanda das famílias por commodities. As famílias estão divididas em decis conforme descrito na seção 2.1 As 10 famílias representativas maximizam uma função de utilidade do tipo Stone-Geary su- 
Tabela 1: Versão Estilizada das Equações do BRIDGE.

\begin{tabular}{|c|c|c|}
\hline Grupo & Dimensão & Código \\
\hline \multicolumn{3}{|c|}{ 1. Composicão dos produtos e dos insumos das indústrias } \\
\hline$X 0(c, d o m, i)=f_{0} \operatorname{csi}\left(X 1 T O T(i), P_{1}\right)$ & $N_{c} N_{i}$ & $(1)$ \\
\hline$X 0 \operatorname{COM}(c)=\sum_{i} X 0(c$, dom,$i)$ & $N_{c}$ & (2) \\
\hline$X 1(c, s, i)=X 1 T O T(i) * f_{1 c s i}\left[P_{1 \text { dom }}(c), P_{1 i m p},(c), A_{1}\right]$ & $N_{c} N_{s} N_{i}$ & (3) \\
\hline$L(i)=X 1 T O T(i) * f_{L i}\left[W, Q(i), A(i)_{L}, A(i)_{P F}\right]$ & $N_{i}$ & $(4)$ \\
\hline$K(i)=X 1 T O T(i) * f_{K i}\left[W, Q(i), A(i)_{L}, A(i)_{P F}\right]$ & $N_{i}$ & (5) \\
\hline \multicolumn{3}{|c|}{ 2. Insumos para a criação de capital e preço dos ativos } \\
\hline$X 2(c, s, i)=X 2 T O T(i) * f_{2 c s i}\left[P_{2 d o m}(c), P_{2 i m p}(c), A_{2}\right]$ & $N_{c} N_{s} N_{h}$ & $(6)$ \\
\hline$P I(i)=f_{P I j}\left(P_{2 d o m}(c), P_{2 i m p}(c), A_{2}\right)$ & $N_{j}$ & $(7)$ \\
\hline \multicolumn{3}{|c|}{ 3. Demanda das famílias por commodities } \\
\hline$X 3(c, s, h)=f_{3 c s}\left[C_{h}, P_{3 \text { dom }}, P_{3 i m p}, A_{3}(h), A_{C / G D P}\right]$ & $N_{c} N_{S} N_{i}$ & $(8)$ \\
\hline$X 3_{S U B}(c, h)=q H * A_{3 S U B}(c, h)$ & $N_{c} N_{h}$ & (9) \\
\hline$X 3_{L U X}(c, h)=\sum_{s} X 3(c, s, h)-X 3_{S U B}(c, h)$ & $N_{c} N_{h}$ & $(10)$ \\
\hline \multicolumn{3}{|l|}{ 4. Exportação } \\
\hline$X 4(c)=f_{4 x}[P E(c)]+A_{4}(c)$ & $N_{c}$ & (11) \\
\hline \multicolumn{3}{|l|}{ 5. Demanda do governo } \\
\hline$X 5(c, s)=A_{5}(c, s) * A_{5 T O T}$ & $N_{c} N_{S}$ & (12) \\
\hline$A_{5} T O T=\sum_{h} D_{h} * A_{5} T_{O T} 2$ & 1 & (13) \\
\hline \multicolumn{3}{|c|}{ 6. Demanda por serviços de margem (por exemplo: famílias) } \\
\hline$X 3 M A R(c, s, m)=A 3 M A R(c, s, m) * \sum_{h} X 3(c, s, h)$ & $N_{c} N_{S} N_{m}$ & $(14)$ \\
\hline \multicolumn{3}{|c|}{ 7. Importações e condição de lucro zero } \\
\hline \multirow{4}{*}{$\begin{array}{l}X_{0 C O M}(c)=\sum_{i} X 1(c, \text { dom }, i)+\sum_{i} X 2(c, \text { dom }, i) \\
+\sum_{h} X 3(c, d o m, h)+X 4(c)+X 5(c, d o m) \\
+\sum_{s} \sum_{m} X 3 M A R(c, s, m) \\
X 0 I M P(c)=\sum_{i} X 1(c, i m p, i)+\sum_{i} X 2(c, i m p, i) \\
+\sum_{h}(c, i m p, h)+X 5(c, i m p) \\
\sum_{c} P_{1 \operatorname{dom}}(c) X 0(c, d o m, i)=\sum_{c} \sum_{S} P_{S}(i) X 1(c, s, i) \\
+W * L(i)+Q(i) * K(i)\end{array}$} & $N_{c}$ & $(15)$ \\
\hline & $N_{c}$ & (16) \\
\hline & & \\
\hline & $N_{i}$ & (17) \\
\hline \multicolumn{3}{|c|}{ 8. Impostos indiretos (por exemplo: exportações) } \\
\hline$T 4(c)=A_{O T}(c) * A_{4 T}(c)$ & $N_{c}$ & $(18)$ \\
\hline \multicolumn{3}{|l|}{ 9. Variáveis Macroeconômicas } \\
\hline$I P C=\Psi_{C P I}\left(P_{3 \text { dom }}, P_{3 i m p}\right)$ & 1 & $(19)$ \\
\hline$W R=(W / I P C) * A_{W R}$ & 1 & (20) \\
\hline$L T O T=\sum_{j} L(j)$ & 1 & (21) \\
\hline$K T O T=\sum_{j} K(j)$ & 1 & $(22)$ \\
\hline $\begin{array}{l}P I B(\text { despesa })=D+\sum_{i} X 2 T O T(i) * \sum_{i} P I(i) \\
+X 5 T O T * \sum_{i} P s(i)+\sum_{c}[P E(c) / \phi] * X 4(c) \\
-\sum_{c}[P M(c) / \phi] * X 0 I M P(c)\end{array}$ & 1 & (23) \\
\hline$P I B_{\text {renda }}=W * L(i)+Q(i) * K(i)+A(i) p f$ & 1 & (24) \\
\hline$P I B_{\text {renda }}=P I B_{\text {despes } a}$ & 1 & $(25)$ \\
\hline
\end{tabular}


Tabela 2: continuação - Versão Estilizada das Equações do BRIDGE.

\begin{tabular}{|c|c|}
\hline $\begin{array}{l}\text { Conjuntos: } \\
i \\
c \\
s\end{array}$ & $\begin{array}{l}\text { Indústria (desagregada em } 60 \text { tipos) } \\
\text { Commodities (desgregada em } 110 \text { tipos }) \\
\text { Origem do insumo: } s=(\text { doméstica,importada })=(\text { dom }, i m p)\end{array}$ \\
\hline Variáveis & \\
\hline$A(i)_{L}$ & Mudança tecnológica no uso de trabalho por indústria \\
\hline$A(i)_{P F}$ & Mudança tecnológica no uso de fatores primários por indústria \\
\hline$A_{0 T}(c)$ & Deslocamento no poder das tarifas para todos os usuários \\
\hline$A_{1}$ & Mudança tecnológica no uso de insumos intermediários \\
\hline$A_{2}$ & Mudança tecnológica no uso de insumos para investimento \\
\hline$A_{3}(c, h)$ & Mudanças nas preferências da família $h$ \\
\hline$A_{3 S U B}(c, h)$ & Mudanças nas preferências no consumo de bens de subsistência \\
\hline$A_{4}(c)$ & Mudanças na demanda externa por commodities nacionais \\
\hline$A_{4 T}(c)$ & Deslocamento no poder das tarifas sobre exportações \\
\hline$A_{5}(c, s)$ & Mudanças exógenas da composição dos gastos do governo \\
\hline$A_{5 T O T}$ & Mudanças exógenas no total de gastos do governo \\
\hline$A_{5 T O T} 2$ & Razão entre o consumo do governo e das famílias \\
\hline$A_{C / P I B}$ & Mudança na razão consumo sobre PIB \\
\hline$A_{W R}$ & Deslocamento no salário real \\
\hline$C_{h}$ & Consumo total da família $h$ \\
\hline$P_{1}$ & Preços domésticos \\
\hline$P_{1 \text { dom }}(c)$ & Preço da commodity doméstica utilizada como insumo intermediário \\
\hline$P_{1 i m p}(c)$ & Preço da commodity importada utilizada como insumo intermediário \\
\hline$P_{2 \text { dom }}(c)$ & Preços das commodities domésticas utilizadas para investimento \\
\hline$P_{2 i m p}(c)$ & Preços das commodities importadas utilizadas para investimento \\
\hline$P_{3 i m p}$ & Preços das commodities importadas utilizadas para consumo \\
\hline$P_{3 \text { dom }}$ & Preços das commodities domésticas utilizadas para consumo \\
\hline$P I B_{\text {despesa }}$ & PIB pelo lado da despesa \\
\hline$P I B_{\text {renda }}$ & PIB pelo lado da renda \\
\hline$X 3_{L U X}(c, h)$ & Parcela destinada ao consumo de bens de luxo por família \\
\hline$X 3_{S U B}(c, h)$ & Parcela destinada ao consumo de bens de subsistência por família \\
\hline$A 3 M A R(c, s, m)$ & Mudanças tecnológicas na oferta de margens para as famílias \\
\hline$I P C$ & índice de preços ao consumidor \\
\hline$K(i)$ & Total de capital utilizado na indústria $i$ \\
\hline KTOT & Estoque de capital total \\
\hline$L(i)$ & Total de trabalho utilizado na indústria $i$ \\
\hline LTOT & Emprego total \\
\hline$P E(c)$ & Preço da moeda estrangeira para exportações \\
\hline
\end{tabular}

jeitas a uma restrição orçamentária. Assumindo que as famílias gastam toda a renda disponível (proveniente dos fatores primários), as funções de demanda (equação 2$)$ são lineares nos preços $\left(P_{3 \text { dom }}, P_{3 i m p}\right)$ e no orçamento familiar, ou renda real disponível que é igual consumo total das Famílias $\left(C_{h}\right)$, bem como de mudanças nas preferências $\left.\left(A_{C / P I B}\right), A_{3}(c, h)\right)$. O composto de consumo da família $h$ pela commodity $c$ pode ser separado em consumo de subsistência ou luxo. Na equação $2, X 3_{S U B}(c, h)$ define a demanda por bens de subsistência que varia de acordo com o crescimento populacional $(q H)$, e mudanças de preferências por bens de subsistência $\left(A_{3 S U B}(c, h)\right)$; por sua vez, a equação 2 define o consumo de luxo como uma parcela residual subtraindo o consumo de subsistência $\left(X 3_{S U B}(c, h)\right)$ do consumo total da commodity $c$ em todas as origens.

O quarto grupo avalia as exportações (equação 2). Basicamente, na versão estilizada, a demanda estrangeira por commodities domésticas $(X 4(c))$ depende do preço da moeda estrangeira $[P E(c)]$ e de uma variável de deslocamento nas preferências externas $\left(A_{4}(c)\right)$. Logo, a demanda por exportações é uma função decrescente do preço da moeda estrangeira. 
Tabela 3: continuação - Versão Estilizada das Equações do BRIDGE.

\begin{tabular}{ll}
\hline$P I(i)$ & Preço efetivo da unidade de capital adicionada \\
$P M$ & Preço da moeda estrangeira para importações \\
$Q(i)$ & Preço do fator capital \\
$T 4(c)$ & Total de impostos indiretos sobre a commodity $c$ \\
$W$ & Preço do fator trabalho \\
$W R$ & Salário Real \\
$X 0(c$, dom, $i)$ & Total da produção doméstica na indústria $i$ \\
$X 0 C O M(c)$ & Produção total doméstica da commodity $c$ \\
$X 0 I M P(c)$ & Importações totais da commodity $c$ \\
$X 1(c, s, i)$ & Demanda do insumo intermediário $c$ da indústria $i$ de to- \\
$X 1(c, d o m, i)$ & das as origens \\
& Demanda do insumo intermediários doméstico $c$ na in- \\
$X 1(c, i m p, i)$ & dústria $i$ \\
& Demanda do insumo intermediário importados $c$ da in- \\
$X 1 T O T(i)$ & dústria $i$ \\
$X 2(c, d o m, i)$ & Nível de atividade da indústria $i$ \\
$X 2(c, s, i)$ & Demanda por insumos domésticos para investimento \\
$X 2(c, i m p, i)$ & Demanda por insumos para investimento \\
$X 2 T O T(i)$ & Demanda por insumos importados para investimento \\
$X 3(c$, dom, $h)$ & Total de investimentos na indústria $i$ \\
& Consumo da família $h$ para a commodity $c$ de origem do- \\
$X 3(c, s, h)$ & méstica \\
$X 3(c, i m p, h)$ & Consumo da família $h$ para a commodity $c$ de origem $s$ \\
$X 3 M A R(c, s, m)$ & Consumo da família $h$ para a commodity $c$ de origem im- \\
& portada \\
$X 4(c)$ & Demanda das famílias por margens por commodity e ori- \\
$X 5(c$, dom $)$ & Demanda estrangeira por commodities domésticas \\
$X 5(c, s)$ & Demanda do governo pela commodity $c$ de origem domés- \\
$X 5(c, i m p)$ & tica \\
$X 5 T O T$ & Demanda do governo pela commodity $c$ de origem $s$ \\
$q H$ & Demanda do governo pela commodity $c$ de origem impor- \\
$\phi$ & tada \\
\hline & Total consumido pelo governo \\
& Crescimento populacional \\
Taxa de câmbio \\
\hline
\end{tabular}

Fonte: Adaptado a partir de Dixon \& Rimmer (2007). 
O quinto grupo exibe a demanda do governo por commodities. O nível e a composição do consumo do governo são determinados exogenamente pelas variáveis de deslocamento $A_{5}(c, s)$ e $A_{5 T O T}$ (equação 2), que permitem respectivamente variações na composição do consumo do governo, e o ajuste dos gastos do governo sujeito a uma restrição orçamentária. Na ausência de choques nas variáveis de deslocamento (equação 2), o consumo agregado do governo $\left(A_{5 T O T 2}\right)$ pode variar em função do consumo total real das famílias. $\mathrm{A}$ demanda por margens pode ser definida para cada um dos agentes do modelo seguindo o mesmo padrão conforme o exemplo apresentado no grupo seis. Neste caso (equação 2) a demanda por serviços de margens (comércio e transportes) pelas famílias, como função da demanda total por determinada commodity e mudanças tecnológicas na oferta de serviços de margens.

O sétimo grupo apresenta as equações de equilíbrio de mercado (marketclearing) para as commodities consumidas localmente, tanto de origem nacional quanto importada. A produção (oferta) das commodities é igual à soma das demandas para o mesmo bem, conforme representada pela equação 2. Da mesma forma, o total importado (equação 2) é equivalente ao total importado por todos os agentes exceto o próprio setor externo, que não pode demandar importações. Como condição de balanceamento, assume-se lucro zero, ou seja, conforme explícito na equação 2 a receita na indústria $i$ é igual ao custo.

O oitavo grupo contém as regras para a definição de impostos sobre as vendas para produtores, investidores, famílias e governo. As variáveis de impostos sobre a venda no modelo linearizado são tratadas como "poder de tarifas". A equação (2) mostra o poder das tarifas indiretas, como o poder da tarifa de exportações $(T 4(c))$ como o produto de variáveis de deslocamento no poder das tarifas de todos os usuários $\left(A_{0 T}(c)\right)$, ou das tarifas de exportações $\left(A_{4 T}(c)\right)$. Essas variáveis de deslocamento permitem aplicar uma redução no poder da tarifa para uma commodity para todos os agentes.

No grupo 9 estão as variáveis macroeconômicas. A primeira equação 2 mostra o índice de preço ao consumidor (IPC), sendo definido pelo composto de preços ao consumidor, tanto de bens nacionais quanto importados $\left(P_{3 \text { dom }}\right.$, $\left.P_{3 i m p}\right)$. O salário real (equação 2) é determinado pelo salário nominal $(W)$ deflacionado pelo IPC, multiplicado por possíveis deslocamentos (mudanças exógenas) no salário real $\left.A_{W R}\right)$. LTOT e KTOT correspondem ao emprego e ao estoque de capital total na economia, respectivamente (equações 2 e 2). Por sua vez, PIB despesa indica o Produto Interno Bruto pela ótica dos gastos, em termos nominais (equação 2), enquanto PIB $B_{\text {renda }}$, representa o PIB sob a ótica dos dispêndios (equação 2), que é, como condição de balanceamento, igual ao PIB despesa (equação 2).

Maiores detalhes sobre a operacionalização do modelo podem ser encontrados no Anexo.

\subsection{Adaptação do modelo}

Para atender os objetivos da pesquisa o modelo foi adaptado para incorporar dados específicos do consumo de serviços domésticos, e assim foi possível mapear com maior precisão o tipo de família que utiliza com mais intensidade o trabalho doméstico (por decil de renda). Adicionalmente, procurou-se identificar a participação dos trabalhadores domésticos nos decis de renda, a fim de se localizar os efeitos dos ganhos de renda da formalização. Essa abertura foi 
possível com os dados da Pesquisa de Orçamento Familiar (POF) do Instituto Brasileiro de Geografia e Estatística IBGE (2012c).

A distribuição das famílias por faixa de renda foi obtida usando os dados da POF $2002 / 2003,{ }^{6}$ referentes à renda mensal por unidade de consumo (Tabela 4). Em seguida, foram criadas as frações de renda consumida para cada produto da matriz, para as dez famílias representativas. Esses resultados, por sua vez, foram utilizados para a desagregação do consumo das famílias (Figura 3) segundo as Contas Nacionais (IBGE 2012c).

Tabela 4: Características dos decis de renda no Brasil pela POF 2002-2003

\begin{tabular}{lcccccc}
\hline Decil & $\begin{array}{c}\mathrm{N}^{\circ} \text { de } \\
\text { Observações }\end{array}$ & População & $\begin{array}{c}\text { Renda } \\
\text { Média }(\mathrm{R} \$)\end{array}$ & $\begin{array}{c}\text { Desvio } \\
(\mathrm{R} \$)\end{array}$ & $\begin{array}{c}\text { Mínimo } \\
(\mathrm{R} \$)\end{array}$ & $\begin{array}{c}\text { Máximo } \\
(\mathrm{R} \$)\end{array}$ \\
\hline 1 & 6.730 & 4.877 .783 & 210,71 & 68,96 & 4 & 305 \\
2 & 6.158 & 4.836 .322 & 379,11 & 43,59 & 306 & 453 \\
3 & 5.606 & 4.869 .806 & 523,81 & 40,63 & 454 & 596 \\
4 & 5.190 & 4.846 .089 & 674,8 & 47,17 & 597 & 758 \\
5 & 4.921 & 4.843 .652 & 859,31 & 60,67 & 759 & 970 \\
6 & 4.390 & 4.861 .636 & $1.103,00$ & 80,07 & 971 & $1.246,00$ \\
7 & 4.225 & 4.847 .143 & $1.431,09$ & 115,03 & $1.247,00$ & $1.652,00$ \\
8 & 3.972 & 4.845 .858 & $1.954,89$ & 195,15 & $1.653,00$ & $2.341,00$ \\
9 & 3.687 & 4.853 .007 & $3.000,83$ & 441,4 & $2.342,00$ & $3.878,00$ \\
10 & 3.689 & 4.853 .342 & $8.000,76$ & $6.617,35$ & $3.881,00$ & $385.250,00$ \\
\hline
\end{tabular}

Fonte: Elaboração própria a partir de dados da POF 2002/2003 IBGE (2012a).

O setor de serviços domésticos descrito nas contas nacionais, e que consta da base de dados do modelo EGC, engloba quaisquer gastos com serviços prestados a domicílio. Desta forma, visando acessar o gasto específico com trabalhadores domésticos foi utilizado o Quadro 19 da POF, que conta com a relação de "despesas com serviços domésticos" por unidade de consumo. Entre essas despesas foram selecionados nove tipos de trabalhadores (Tabela 5) que constituem o grupo de "trabalhadores domésticos", conforme escopo da presente pesquisa. As demais categorias foram incluídas em "outros serviços a domicílio", os quais constituem uma parcela crescente com a renda, porém pequena em termos do gasto total com serviços domésticos para todos os decis (Tabela 6).

Se pelo lado do consumo a relação entre os decis de renda e os gastos com trabalho doméstico é positiva (Tabela 7), pelo lado dos rendimentos, como esperado, a relação é inversa (Tabela 8). Para obter a renda dos trabalhadores domésticos nos dados da POF foram considerados todos os indivíduos que se declararam "Trabalhadores Domésticos” como posição da ocupação e que possuem renda ${ }^{7}$ diferente de zero.

Não obstante, a renda por trabalhador seja maior nos decis mais elevados, a importância da renda proveniente de trabalhos domésticos é decrescentes com os decis, chegando a $9,8 \%$ da renda total do primeiro decil, e apenas

\footnotetext{
${ }^{6}$ Já estão disponíveis os dados para a POF 2007/2008, no entanto, o uso dos dados de 2002/2003 se justifica por duas razões: i) a base de dados do modelo de EGC foi calibrada para 2005 , tendo como núcleo central os dados da matriz insumo-produto brasileira de 2005 para a qual, entre outras informações, foram utilizados os dados da POF 2002/2003, e ii) a estrutura de consumo, ou seja, a participação de cada produto na cesta de consumo das famílias não muda de forma significativa entre as duas pesquisas.

${ }^{7}$ Foi utilizada a variável de "valor do rendimento bruto deflacionado anualizado".
} 


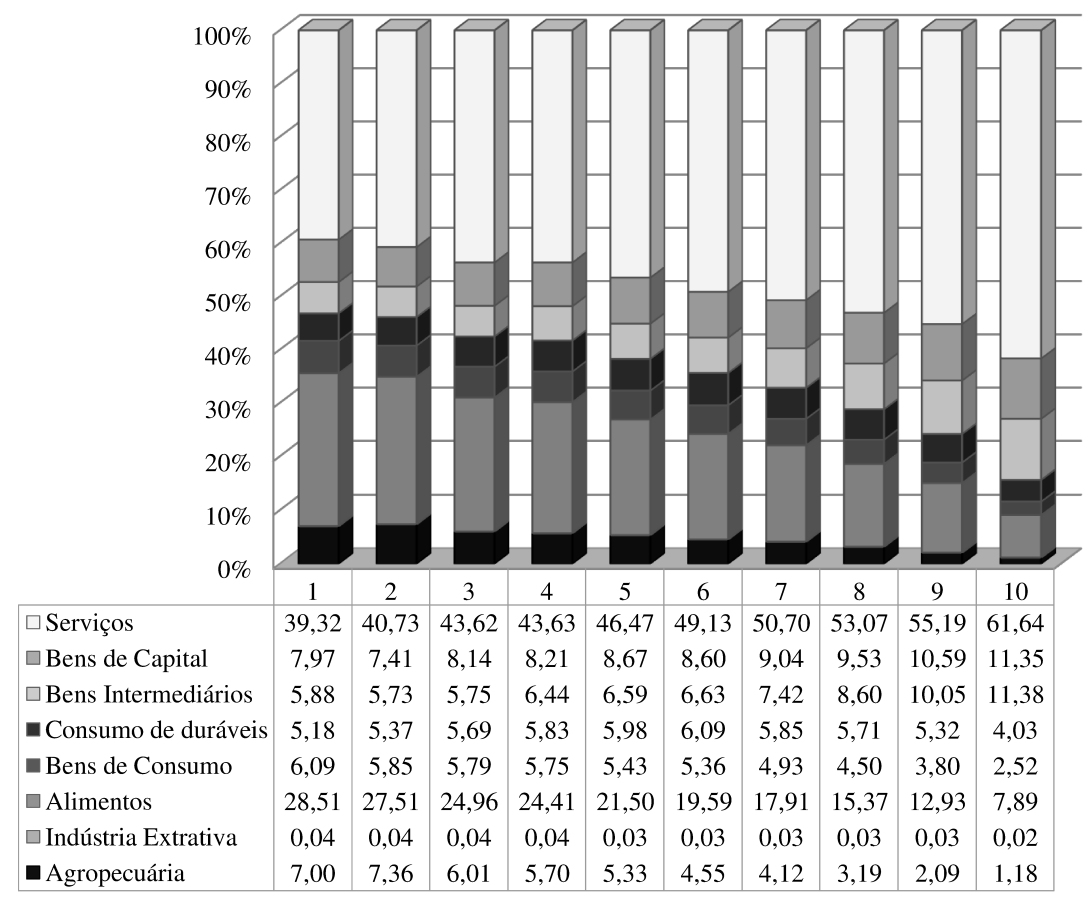

Elaboração própria a partir de dados da POF 2002/2003 (IBGE 2012a).

Figura 3: Participação dos produtos no consumo das famílias, por decil de renda (setores agregados).

Tabela 5: Serviços que compõem as despesas com trabalhadores domésticos pela POF

\begin{tabular}{ll}
\hline Código POF & Serviço \\
\hline 101 & Empregado \\
201 & Cozinheiro \\
301 & Faxineiro \\
401 & Babá \\
801 & Arrumadeira \\
1301 & Lavadeira \\
1401 & Ajudante de cozinha \\
1501 & Passadeira (empregada) \\
1701 & Lavadeira e passadeira \\
\hline Fonte: Elaboração própria a partir de dados da \\
POF 2002/2003 IBGE (2012a).
\end{tabular}


Tabela 6: Despesas com serviços domésticos e outros serviços, por decil de renda, a partir dos dados da POF 2002/2003, por decis de renda

\begin{tabular}{ccccc}
\hline & \multicolumn{2}{c}{$\begin{array}{c}\text { Participação em relação } \\
\text { ao total de "Serviços domésticos" }\end{array}$} & \multicolumn{2}{c}{ Participação por decil } \\
\hline Decil & Outros serviços & T. domésticos & Outros serviços & T.domésticos \\
\hline 1 & 19,88 & 80,12 & 0,99 & 0,36 \\
2 & 4,48 & 95,52 & 0,59 & 1,13 \\
3 & 7,37 & 92,63 & 0,83 & 0,94 \\
4 & 4,38 & 95,62 & 0,56 & 1,10 \\
5 & 6,58 & 93,42 & 1,31 & 1,68 \\
6 & 11,14 & 88,86 & 3,98 & 2,86 \\
7 & 5,36 & 94,64 & 2,62 & 4,16 \\
8 & 7,93 & 92,07 & 8,54 & 8,92 \\
9 & 5,11 & 94,89 & 11,01 & 18,39 \\
10 & 9,38 & 90,62 & 69,57 & 60,47 \\
\hline Total & 8,25 & 91,75 & 100,00 & 100,00 \\
\hline
\end{tabular}

Fonte: Elaboração própria a partir de dados da POF 2002/2003 IBGE (2012a).

Tabela 7: Distribuição do consumo por Serviços Domésticos e demais bens e serviços, por decil de renda (POF, 2002/2003)

\begin{tabular}{ccc}
\hline Decil & Serviços Domésticos & Outros bens e serviços \\
\hline 1 & 0,41 & 2,73 \\
2 & 1,09 & 3,47 \\
3 & 0,93 & 4,33 \\
4 & 1,06 & 5,16 \\
5 & 1,65 & 6,09 \\
6 & 2,95 & 7,40 \\
7 & 4,04 & 9,22 \\
8 & 8,89 & 11,80 \\
9 & 17,78 & 16,06 \\
10 & 61,22 & 33,74 \\
\hline Total & 100,00 & 100,00 \\
\hline
\end{tabular}

Fonte: Elaboração própria a partir de dados da POF 2002/2003 IBGE (2012a). 
0,19\% no décimo decil, conforme pode ser observado na Figura 4, evidenciando o caráter redistributivo do aumento nos salários desses trabalhadores.

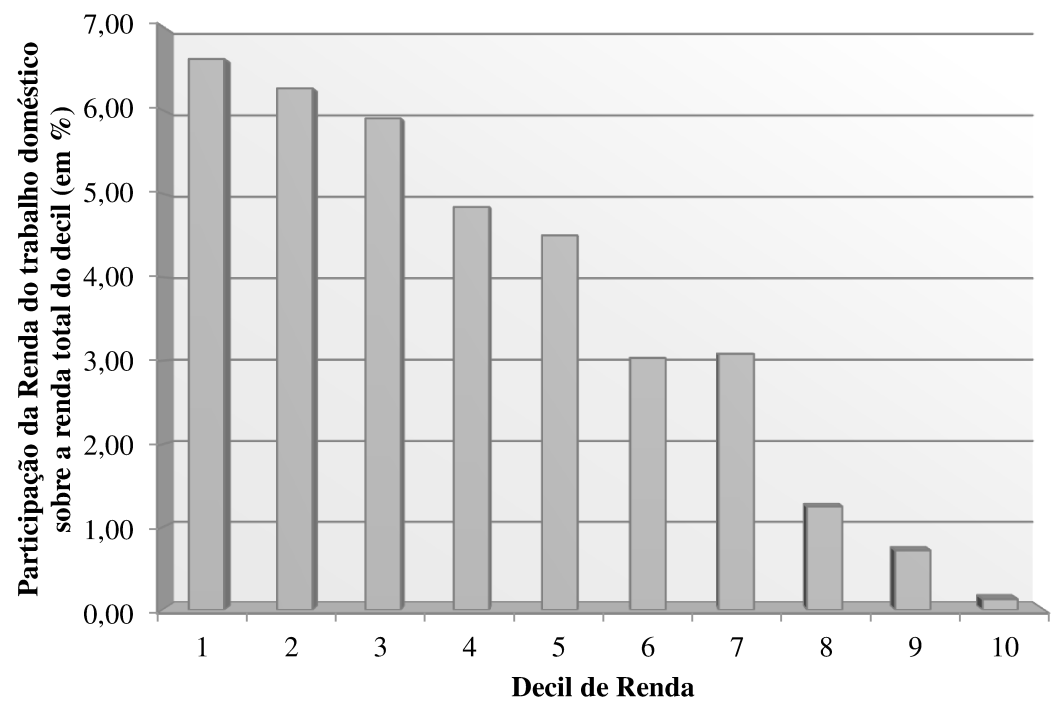

Fonte: Elaboração própria a partir de dados da POF 2002/2003 (IBGE 2012a).

Figura 4: Participação da renda proveniente de trabalhos domésticos na renda total do decil.

A composição dos decis por gênero (Tabela 9) deixa claro o predomínio de mulheres na profissão, em todos os níveis de renda. Enquanto para outros trabalhadores a proporção de mulheres é crescente ao longo dos decis, para trabalhadores domésticos a proporção se mantém semelhante, com exceção do décimo decil, no qual a participação dos homens aumenta para 17,07\%. Para toda a população, $92,60 \%$ dos trabalhadores domésticos são mulheres enquanto para outros trabalhadores essa proporção é de apenas $34,34 \%$.

Não obstante a distribuição por gênero entre os decis seja semelhante, a distribuição por cor ilustra a desigualdade de renda entre bancos e negros na população brasileira (Tabela 6). Para o primeiro decil, 69,41\% da população é negra , enquanto para o último decil apenas $23,38 \%$ se declararam negros. No caso do trabalho doméstico o percentual de trabalhadores brancos é de $43,16 \%$, contra $56,84 \%$ para os demais trabalhadores, porém a distribuição em cada decil é semelhante.

Desta forma, qualquer aumento na renda do trabalho doméstico pode ter efeitos redistributivos progressivos, na medida em que transfere renda dos decis mais altos para os decis mais baixos. Para captar esse efeito foram utilizados os dados da Pesquisa Mensal do Emprego - PME (IBGE 2012b), por meio dos quais é possível observar a variação dos salários ao longo do tempo. ${ }^{8}$

\footnotetext{
${ }^{8}$ A opção pela PME se deve a possibilidade de análise de um período mais longo (chegando a 2011). No entanto, um fator limitante é que a pesquisa é realizada apenas em regiões metropolitanas, onde os salários são em média maiores. Não obstante, para a simulação foi utilizada apenas a variação dos salários e não o seu montante, logo, parte-se do pressuposto de que mesmo com montantes de salário diferentes, a variação de salários na no Brasil segue a variação das regiões metropolitanas.
} 
Tabela 8: Renda deflacionada anual média de trabalhadores domésticos e não-domésticos por decil de renda (POF, 2002/2003)

\begin{tabular}{|c|c|c|c|c|c|c|}
\hline \multirow[b]{2}{*}{ Decil } & \multicolumn{3}{|c|}{ Outros Trabalhadores } & \multicolumn{3}{|c|}{ Trabalhadores domésticos } \\
\hline & Número* & $\begin{array}{l}\text { Renda anual } \\
\text { média }\end{array}$ & $\begin{array}{l}\text { Renda mensal } \\
\text { média }^{* *}\end{array}$ & Número* & $\begin{array}{l}\text { Renda anual } \\
\text { média }\end{array}$ & $\begin{array}{l}\text { Renda mensal } \\
\text { média }^{* *}\end{array}$ \\
\hline 1 & 4.785 .709 & 967,46 & 80,62 & 605.055 & 831,33 & 69,28 \\
\hline 2 & 5.135 .870 & $1.705,65$ & 142,14 & 676.012 & $1.326,90$ & 110,57 \\
\hline 3 & 5.755 .980 & $2.189,03$ & 182,42 & 802.231 & $1.508,29$ & 125,69 \\
\hline 4 & 6.506 .801 & $2.843,18$ & 236,93 & 836.030 & $1.722,43$ & 143,54 \\
\hline 5 & 7.445 .331 & $3.371,24$ & 280,94 & 932.962 & $1.940,06$ & 161,67 \\
\hline 6 & 7.773 .976 & $4.360,70$ & 363,39 & 805.133 & $2.012,09$ & 167,67 \\
\hline 7 & 8.484 .628 & $5.362,64$ & 446,89 & 855.038 & $2.584,68$ & 215,39 \\
\hline 8 & 9.182 .805 & $7.263,58$ & 605,30 & 536.295 & $2.405,39$ & 200,45 \\
\hline 9 & 9.306 .724 & $11.067,27$ & 922,27 & 365.612 & $3.118,06$ & 259,84 \\
\hline 10 & 9.047 .207 & $28.185,49$ & $2.348,79$ & 132.502 & $3.698,06$ & 308,17 \\
\hline Total & 73.425 .031 & - & - & 6.546 .870 & - & - \\
\hline
\end{tabular}


Tabela 9: Distribuição dos trabalhadores por sexo (em \%) em cada decil de renda

\begin{tabular}{ccccccc}
\hline & \multicolumn{2}{c}{ Empregados Domésticos } & \multicolumn{2}{c}{ Outros Trabalhadores } & \multicolumn{2}{c}{ Total } \\
\cline { 2 - 6 } Decil & Feminino & Masculino & Feminino & Masculino & Feminino & Masculino \\
\hline 1 & 93,37 & 6,63 & 23,78 & 76,22 & 32,45 & 67,55 \\
2 & 91,63 & 8,37 & 26,68 & 73,32 & 35,08 & 64,92 \\
3 & 92,19 & 7,81 & 27,98 & 72,02 & 36,71 & 63,29 \\
4 & 93,19 & 6,81 & 28,84 & 71,16 & 36,91 & 63,09 \\
5 & 94,09 & 5,91 & 31,79 & 68,21 & 39,43 & 60,57 \\
6 & 91,84 & 8,16 & 33,29 & 66,71 & 39,23 & 60,77 \\
7 & 93,31 & 6,69 & 35,11 & 64,89 & 40,87 & 59,13 \\
8 & 93,58 & 6,42 & 38,79 & 61,21 & 41,94 & 58,06 \\
9 & 91,03 & 8,97 & 40,25 & 59,75 & 42,23 & 57,77 \\
10 & 82,93 & 17,07 & 42,21 & 57,79 & 42,81 & 57,19 \\
\hline Total & 92,60 & 7,40 & 34,34 & 65,66 & 39,45 & 60,55 \\
\hline
\end{tabular}

Fonte: Elaboração própria a partir de dados da POF 2002/2003 IBGE (2012a).

Tabela 10: Distribuição dos trabalhadores por cor (em \%) em cada decil de renda

\begin{tabular}{ccccccc}
\hline & \multicolumn{2}{c}{ Empregados Domésticos } & \multicolumn{2}{c}{ Outros Trabalhadores } & \multicolumn{2}{c}{ Total } \\
\cline { 2 - 7 } Decil & Brancos & Negros & Brancos & Negros & Brancos & Negros \\
\hline 1 & 29,07 & 70,93 & 30,81 & 69,19 & 30,59 & 69,41 \\
2 & 35,59 & 64,41 & 34,53 & 65,47 & 34,67 & 65,33 \\
3 & 38,66 & 61,34 & 36,65 & 63,35 & 36,93 & 63,07 \\
4 & 37,68 & 62,32 & 43,35 & 56,65 & 42,63 & 57,37 \\
5 & 43,46 & 56,54 & 46,63 & 53,37 & 46,24 & 53,76 \\
6 & 47,78 & 52,22 & 51,85 & 48,15 & 51,44 & 48,56 \\
7 & 51,91 & 48,09 & 59,66 & 40,34 & 58,89 & 41,11 \\
8 & 53,51 & 46,49 & 60,21 & 39,79 & 59,82 & 40,18 \\
9 & 48,57 & 51,43 & 66,07 & 33,93 & 65,39 & 34,61 \\
10 & 64,20 & 35,80 & 76,81 & 23,19 & 76,62 & 23,38 \\
\hline Total & 43,16 & 56,84 & 54,10 & 45,90 & 53,14 & 46,86 \\
\hline
\end{tabular}

Fonte: Elaboração própria a partir de dados da POF 2002/2003 IBGE (2012a).

\subsection{Desenho da estratégia analítica}

De porte das informações específicas descritas na seção anterior serão captados dois efeitos diretos do aumento da renda dos trabalhadores domésticos no período 2006-2011: i) a elevação dos preços para os empregadores e ii) os ganhos de renda dos trabalhadores domésticos.

Os mecanismos de dinâmica recursiva permitem a utilização explicitamente temporal do modelo EGC, em que as variáveis endógenas se ajustam ao longo do período de análise após um choque inicial, ou choques consecutivos. Para tanto, a operacionalização de modelos EGC exige que sejam estabelecidas hipóteses de simulação, ou o conjunto de variáveis exógenas e endógenas, que definem o chamado "fechamento" do modelo.

Sendo assim, simulações e análises podem ser efetuadas a partir de dois fechamentos: base e de política. O fechamento base estabelece o conjunto de choques e variáveis endógenas de forma a reproduzir um cenário de referência (neste caso, o cenário observado no período 2006-2011). O fechamento de política estabelece as variáveis endógenas e exógenas de forma a permitir choques exógenos específicos, para determinadas variáveis e períodos, desenca- 
deando alterações nas variáveis endógenas, por meio de mudanças nos preços relativos e quantidades reais.

Serão realizados, portanto, dois conjuntos de simulações ( Tabela 10): i) o primeiro refere-se ao crescimento observado entre 2006 e 2011; e ii) o segundo incorpora um conjunto de simulações, i. e., mantém constante o número de trabalhadores em relação ao cenário base e estabelece um aumento de 10,94\% ao ano no preço do trabalho doméstico (como consequência da carga tributária decorrente da formalização) e um aumento uniforme e permanente na renda dos trabalhadores domésticos, ${ }^{9}$ cujo valor foi ponderado com base na participação da renda do trabalho doméstico na renda total para cada decil (Tabela 12).

Tabela 11: Resumo das simulações de modificações de renda dos empregados domésticos e dos preços dos serviços domésticos

\begin{tabular}{lll}
\hline Simulação & Descrição & Período \\
\hline Cenário Base & Cenário macroeconômico observado. & 2006 a 2011 \\
Fechamento & $\begin{array}{l}\text { 1. Aumento no custo de serviços domésticos } \\
\text { de Política }\end{array}$ & 20 10,95\% anuais \\
& $\begin{array}{l}\text { 2. Aumento na renda do trabalho doméstico } 2011 \\
\text { de 10,95\% anuais, distribuídos por decil de renda. }\end{array}$ \\
\hline Fonte: Elaboração própria.
\end{tabular}

Fonte: Elaboração própria.

Tabela 12: Aumento da renda do trabalho doméstico distribuído por decil de renda

\begin{tabular}{ccc}
\hline Decil & $\begin{array}{c}\text { Participação da renda do trabalho } \\
\text { doméstico por decil (em \%) }\end{array}$ & $\begin{array}{c}\text { Aumento observado na renda do trabalho } \\
\text { doméstico distribuído por decil (em \%) }\end{array}$ \\
\hline 1 & 9,79 & 1,07 \\
2 & 9,28 & 1,01 \\
3 & 8,76 & 0,95 \\
4 & 7,22 & 0,79 \\
5 & 6,72 & 0,73 \\
6 & 4,56 & 0,49 \\
7 & 4,63 & 0,50 \\
8 & 1,89 & 0,20 \\
9 & 1,09 & 0,11 \\
10 & 0,19 & 0,02 \\
\hline
\end{tabular}

Fonte: Elaboração própria.

Desta forma, o resultado da simulação, representa um desvio em relação ao cenário base (ou de referência) observado no período. Em termos metodológicos, a taxa de crescimento do cenário base não altera os resultados do desvio decorrente da simulação, logo, a simulação de política representa a parcela do resultado observado, que decorre exclusivamente das alterações no mercado de serviços domésticos. Todas as simulações foram realizadas no software RunDynam. ${ }^{10}$

\footnotetext{
${ }^{9} \mathrm{O}$ aumento de renda foi pressuposto homogêneo para todos os trabalhadores, independente de suas características (como seu nível de renda desses trabalhadores, e condição como trabalhador formal ou informal).

${ }^{10} \mathrm{O}$ RunDynam é um aplicativo customizado do Gempack 10.0 (Harrison \& Pearson 2002) para simulações de dinâmica recursiva e modelos intertemporais. Maiores detalhes em ht tp : / / www.monash.edu.au/policy.
} 


\section{Resultados}

Em termos gerais as mudanças ocorridas nos serviços domésticos teriam provocado alterações no nível de produção, emprego, salários e consumo da economia brasileira. Do crescimento acumulado do PIB entre 2006 e 2011 (cenário base), $0,58 \%$ ou cerca de $\mathrm{R} \$ 19$ bilhões de reais a preços de $2011,{ }^{11}$ podem ser atribuídos ao aumento da renda do trabalho doméstico e ao correspondente crescimento nos custos desses serviços. ${ }^{12} \mathrm{O}$ resultado sobre o emprego agregado seria de $0,77 \%$, ou cerca de 630 mil postos de trabalho. ${ }^{13}$

O aumento na renda dos trabalhadores domésticos e da elevação na renda real se reflete no acréscimo de 1,90\% no consumo das famílias. Conforme o esperado, esse aumento beneficia principalmente os decis com menor renda, por concentrarem a maior parte dos ganhos provenientes do trabalho doméstico. Do crescimento no consumo real do primeiro decil, entre 2006 e 2011, $6,61 \%$ podem ser atribuídos ao aumento da renda do trabalho domésticos ( $\mathrm{Ta}$ bela 13). Esse valor decresce, com os decis, chegando a $0,13 \%$ no decil mais rico.

Tabela 13: Variação do consumo real das famílias por decil de renda decorrentes das modificações de renda das empregadas domésticas e dos preços dos serviços domésticos - resultados simulados.

\begin{tabular}{cc}
\hline Famílias por decil de renda & Variação acumulada de 2006 a 2011 (em \%) \\
\hline 1 & 6,61 \\
2 & 6,26 \\
3 & 5,90 \\
4 & 4,84 \\
5 & 4,50 \\
6 & 3,03 \\
7 & 3,08 \\
8 & 1,25 \\
9 & 0,72 \\
10 & 0,13 \\
\hline
\end{tabular}

Fonte: Elaboração própria.

As alterações no bem-estar mostram-se positivas para todos os decis (Figura 5), tanto quando mensuradas em termos de variação da renda compensadora (que mensura a compensação monetária necessária — dada a variação dos preços - para que cada uma das dez famílias representativas mantenha o mesmo nível de satisfação inicial), quanto por meio da variação compensadora (que mede a quantidade máxima de renda que o consumidor estaria disposto a pagar para evitar a variação de preço e continuar consumindo a mesma combinação de bens a anterior ao choque).

\footnotetext{
${ }^{11}$ Valor em reais calculado a partir do PIB de 2005 a preços de 2011, dados estimados pelo IPEA (2012a). Em termos exatos, $\mathrm{R} \$ 18.869 .634 .196$ reais.

${ }^{12}$ Ente 2006 e 2011 o crescimento do PIB brasileiro foi de $27,7 \%$, ou seja, o efeito das modificações do mercado de serviços domésticos corresponderia a cerca de $2 \%$ do crescimento observado no período.

${ }^{13}$ Número de pessoas ocupadas calculado a partir da população ocupada em 2005, segundo IPEA (2012b). Em números exatos, 632.946 ocupações.
} 


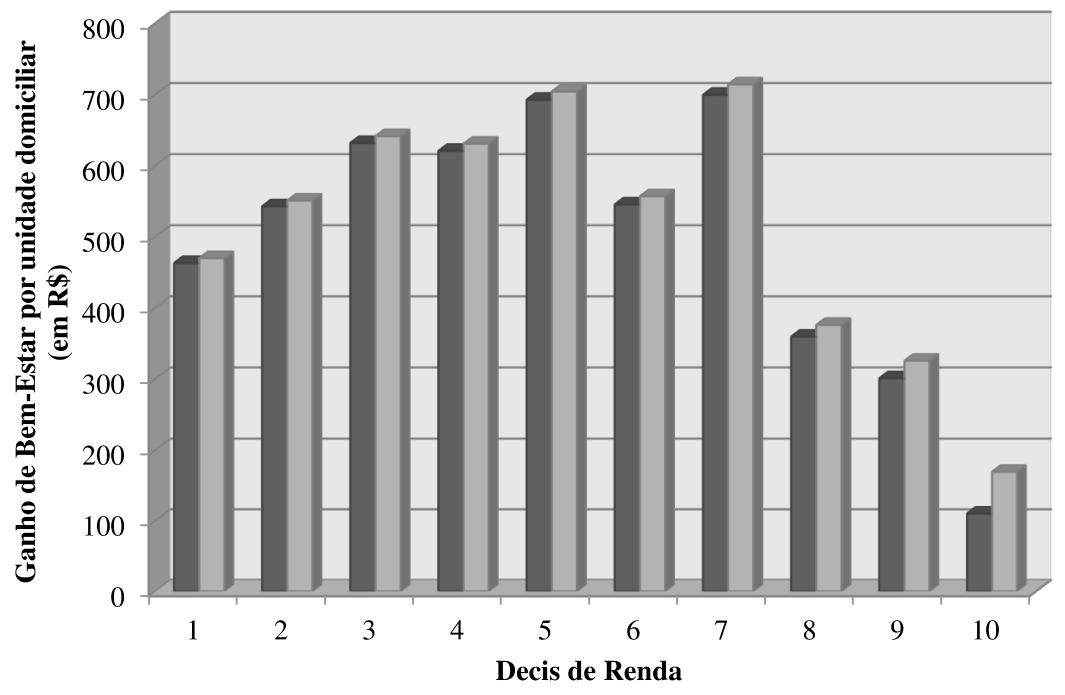

Fonte: Elaboração própria a partir dos resultados das simulações.

Figura 5: Ganhos monetários de bem-estar, por decil de renda na economia brasileira, decorrentes das modificações de renda das empregadas domésticas e dos preços dos serviços domésticos — resultados simulados (em reais de 2005)

Pode-se observar que todas as famílias têm seu bem-estar elevado, sendo que a maior variação está nos decis de renda intermediários. Isso ocorre devido a dois fatores: i) nesses decis, a parcela da renda proveniente do trabalho doméstico é alta, e ao mesmo tempo se consume uma pequena proporção desses serviços, consequentemente os decis intermediários recebem os benefícios do choque positivo na renda, e são pouco afetados pelo aumento de preços; ii) por outro lado, para os primeiros decis, que possuem menores rendimentos (apenas $1,17 \%$ da renda do trabalho nacional, ou cerca de 10 bilhões de reais, para o primeiro decil), as variações equivalente e compensadora são em termos monetários menores, não obstante representem um ganho de bem-estar maior em proporção a sua renda inicial.

Pelo lado da produção, os setores se ajustam aos choques de renda e preços, alterando sua produção e o uso de fatores produtivos (trabalho). A elevação da renda das famílias acaba deslocando parte dos fatores produtivos para os setores mais associados ao consumo das famílias, que aumentam o uso de trabalho e a produção. Do outro lado, setores voltados à exportação ou investimento, reduzem marginalmente sua produção e emprego. Assim, setorialmente, o efeito positivo das modificações simuladas recai sobre os setores de "bens de consumo", com aumento de $0,85 \%$ na produção e $2,29 \%$ no emprego do setor (Tabela 13).

Também estão entre os mais beneficiados a "indústria de alimentos", os "serviços", os "bens de consumo duráveis" e a "agropecuária"; enquanto os setores tradicionalmente destinados ao consumo intermediário, como a "indústria extrativa", "a indústria de bens intermediários" e a "indústria de bens de capital" sofreram um desvio negativo na produção e no emprego. Tais mudanças tornam-se claramente explicadas pela estrutura de consumo das famílias 
Tabela 14: Variação acumulada percentual entre 2006 e 2011 na produção e no emprego setorial da economia brasileira decorrentes das modificações de renda das empregadas domésticas e dos preços dos serviços domésticos - resultados simulados

\begin{tabular}{lcc}
\hline Setor & Produção & Emprego \\
\hline Agropecuária & 0.23 & 0.28 \\
Indústria Extrativa & -1.04 & -4.35 \\
Alimentos & 0.53 & 1.00 \\
Bens de Consumo & 0.85 & 2.29 \\
Consumo de Duráveis & 0.33 & 0.22 \\
Bens Intermediários & -0.74 & -1.76 \\
Bens de Capital & -1.11 & -1.89 \\
Serviços & 0.66 & 1.27 \\
\hline
\end{tabular}

Fonte: Elaboração própria a partir dos resultados das simulações.

(Figura 3), em especial, pela estrutura de consumo dos decis mais baixos, cujo consumo de bens de subsistência é elevado.

Para uma maior desagregação setorial é possível observar que os setores cujas vendas são destinadas ao consumo das famílias são bastante beneficiadas, como é o caso eletrodomésticos, ${ }^{14}$ e diversos setores de serviços relacionados á saúde (Tabela 14). No que tange ao aumento do emprego, a lógica permanece a mesma, e os setores mais beneficiados seriam "atividades hospitalares" e "produtos farmacêuticos", com aumento de 5,08 e 4,93\% respectivamente. Conforme o esperado, os maiores desvios negativos ocorreram na indústria, com redução no emprego de 7,19\% para o "minério de ferro" e 5,55\% em "resinas e elastômeros".

\section{Considerações finais}

O crescimento econômico do início do século XXI, combinado a diversas políticas de transferência de renda e incentivos sociais tem desencadeado aumentos permanentes de bem-estar para as classes menos favorecidas da população brasileira, que vêm ampliadas as oportunidades de emprego. Entre os beneficiados estão os trabalhadores domésticos, cujos salários têm crescido acima da média das demais ocupações, não obstante mantenham-se distantes da média geral de salários.

Nesse contexto, a presente pesquisa buscou investigar as consequências econômicas das mudanças no mercado de serviços domésticos entre 2005 e 2011. Para tanto, foi utilizado um modelo de equilíbrio geral computável com dinâmica recursiva (BRIDGE), com detalhamento para 117 produtos, 60 setores e 10 famílias representativas distribuídas por decil de renda. Assim, foi possível acessar não apenas o impacto direto sobre o setor de serviços domésti-

\footnotetext{
${ }^{14}$ Entre 2006 e 2011 as vendas de eletrodomésticos e móveis cresceram 91\%. Assim, o resultado do modelo indica que sem as alterações no mercado de serviços domésticos esse crescimento seria 2,69 pontos percentuais menor.
} 
Tabela 15: Principais variações setoriais na produção e no emprego da economia brasileira decorrentes das modificações de renda das empregadas domésticas e dos preços dos serviços domésticos - resultados simulados (entre 2006 e 2011)

\begin{tabular}{|c|c|}
\hline Setores mais beneficiados & Variação \% Acumulada \\
\hline \multicolumn{2}{|l|}{ Produção } \\
\hline Atividades hospitalares & 4.62 \\
\hline Eletrodomésticos & 2.69 \\
\hline Fab. de Produtos Farmacêuticos & 2.27 \\
\hline Educação e Saúde Pública & 1.90 \\
\hline Adm. Pública e Seguridade Social & 1.88 \\
\hline Serviços de Manut. e Reparação & 1.58 \\
\hline Artigos do Vestuário & 1.29 \\
\hline Assistência Médica Hospitalar & 1.20 \\
\hline Perfumaria e Outros & 1.07 \\
\hline Indústrias Diversas & 1.03 \\
\hline \multicolumn{2}{|l|}{ Emprego } \\
\hline Atividades hospitalares & 5.08 \\
\hline Fabricação de prod. farmacêuticos & 4.93 \\
\hline Eletrodomésticos & 4.15 \\
\hline Serviços de manut. e reparação & 3.07 \\
\hline Perfumaria e outros & 2.74 \\
\hline Assistência média hospitalar & 2.22 \\
\hline Administração púb. e seg. social & 2.20 \\
\hline Indústrias diversas & 2.15 \\
\hline Saúde pública & 2.08 \\
\hline Educação pública & 2.06 \\
\hline
\end{tabular}

Fonte: Elaboração própria a partir dos resultados das simulações.

cos como também as mudanças de renda, consumo, e bem-estar para famílias de realidades econômicas distintas.

Seguindo o arcabouço dos modelos de equilíbrio geral com dinâmica recursiva, a partir do cenário macroeconômico observado no período foi realizada a seguinte simulação: i) o número de trabalhadores domésticos é mantido fixo em relação ao cenário base; iii) o preço do trabalho doméstico cresce anualmente 10,95\%; e iii) a renda dos trabalhadores domésticos aumenta anualmente em 10,95\% - distribuídos de acordo com a participação desses trabalhadores em cada decil de renda. Os valores utilizados no choque foram retirados dos dados observados da PME (IBGE 2012b).

Os resultados mostram que $0,58 \%$ do crescimento econômico do período ou o equivalente a 18.869.634.196 reais, podem ser atribuídos às mudanças no mercado de trabalhadores domésticos, que desencadearam aumentos de renda principalmente para as classes menos favorecidas da economia brasileira. Desta forma, a valorização do trabalho doméstico permitiu o aumento do consumo principalmente de bens essenciais, como eletrodomésticos e serviços de saúde, aumentando o nível de bem-estar geral da população.

Ou seja, de forma geral, pode-se dizer, que, no período analisado, a demanda por serviços domésticos foi elástica o suficiente para acomodar eleva- 
ções de preços, ao mesmo tempo, em que os efeitos indiretos dessa transferência de renda entre os decis mais ricos da distribuição para o mais pobres, geraram mudanças no padrão de consumo que beneficiaram a população como um todo, levando a resultados positivos sobre o emprego e a renda agregada.

O impacto econômico do aumento da renda desses trabalhadores indica um caminho para políticas públicas, mostrando que por meio da valorização de categorias de trabalho tradicionalmente marginais na economia brasileira é possível melhorar as condições de vida da população de baixa renda, aumentando, ao mesmo tempo, o bem-estar de toda a população.

Assim, embora a elevação da renda dos trabalhadores domésticos seja consequência da combinação de diversos fatores, é possível inferir (dados os pressupostos do modelo), que quaisquer aumentos de renda distribuídos na população conforme o comportamento da oferta e consumo de serviços domésticos levariam a resultados semelhantes.

Neste sentindo, de forma indireta, os resultados encontrados sugerem quais seriam as consequências do processo de formalização e inclusão do trabalho doméstico nos diretos trabalhistas, que levaria, de forma semelhante à simulação apresentada, ao aumento da renda de uma parcela da população e a elevação dos custos desses serviços. No entanto, vale ressaltar, que embora o número de trabalhadores com carteira assinada tenha variado pouco no período (de 35,64 para $38,68 \%$ ) na simulação realizada não foi feita a distinção entre trabalhadores formais e informais, considerando apenas o total de salários pagos líquidos de impostos. Sem essa distinção, não foi possível considerar os efeitos em termos de variações nos encargos trabalhistas que poderiam modificar marginalmente o consumo das famílias empregadoras, porém sem afetar diretamente o recebimento líquido das famílias contratadas para serviços domésticos.

\section{Agradecimentos}

Os autores agradecem o financiamento da ONU Mulheres por meio do IPC-IG UNDP.

\section{Referências Bibliográficas}

Departamento Intersindical de Estatística e Estudos Econômicos (2006), Incentivo a formalização do emprego doméstico, Nota Técnica 25.

URL: Disponivel em: <http://www.dieese.org.br/notatecnica/2006/notatec25empregoDomestico.pdf>

Dixon, P. B. \& Parmenter, B. R. (1996), Computable general equilibrium modelling for policy analysis and forecasting, Vol. 1, Handbook of computational economics. Elsevier.

Dixon, P. B., R., P. B., Sutton, J. M. \& P., V. D. (1982), ORANI: A Multisectoral Model of the Australian Economy, 1 edn, North-Holland, Amsterdam.

Dixon, P. B. \& Rimmer, M. T. (2007), Dynamic General Equilibrium Model for Forecasting and Policy: A Practical Guide and Documentation of MONASH, Vol. 1, Emerald Group Publishing Limited. 
Dixon, P. \& Rimmer, M. (1998), Forecasting and policy analysis with a dynamic cge model of australia, Working Paper OP-90.

URL: Disponivel em: <http://www.copsmodels.com/ftp/workpapr/op-90.pdf>

Domingues, E. P.and Carvalho, T. S., Betarelli Junior, A. A., Magalhães, A. S. \& Santiago, F. S. (2010), 'Repercussões setoriais e regionais da crise econômica de 2009 no brasil: simulações em um modelo de equilíbrio geral computável de dinâmica recursiva', Anais do $38^{\circ}$ Encontro Nacional de Economia da Associação Nacional de Centros de Pós-graduação em Economia.

Domingues, E. P.and Magalhães, A. S. \& Faria, W. R. (2009), 'Infraestrutura, crescimento e desigualdade regional: uma projeção dos impactos dos investimentos do pac em minas gerais', Pesquisa e Planejamento Econômico 39(1), 121-158.

Fochezatto, A. \& Souza, N. J. (2000), 'Estabilização e reformas estruturais no brasil após o plano real: uma análise de equilíbrio geral computável', Pesquisa e Planejamento Econômico 30(3), 395-426.

Frisch, R. (1959), 'A complete scheme for computing all direct and cross demand elasticities in a model with many sectors', Econometrica 27(2), 177196.

Haddad, E. A. \& Domingues, E. P. (2001), 'Efes - um modelo aplicado de equilíbrio geral para a economia brasileira: projeções setoriais para 19992004', Estudos Econômicos 31(1), 89-125.

Harrison, J. \& Pearson, K. (2002), Adding accounting-related behaviour to a model implemented using gempack, Working paper.

URL: Disponivel em: <http://www.monash.edu.au/policy/elecpapr/c12-01.htm>

Hasegawa, M. M. (2003), 'Políticas públicas na economia brasileira: uma aplicação do modelo mibra, um modelo inter-regional aplicado de equilíbrio geral', Escola Superior de Agricultura -Luiz de Queiroz- da Universidade de São Paulo (ESALQ/USP). Tese de Doutorado.

Hoffmann, R. (2007), Elasticidades-renda das despesas e do consumo de alimentos no brasil em 2002-2003, in F. G. Silveira, L. M. Servo, T. Menezes \& S. F. Piola, eds, 'Gasto e consumo das famílias brasileiras contemporâneas', Vol. 2, IPEA.

Horridge, M. (2006), 'Orani-g: A generic single-country computable general equilibrium model', Centre of Policy Studies and Impact Project, Monash University.

IBGE (2010), Algumas das principais características dos trabalhadores domésticos vis a vis a população ocupada, Technical report, Instituto Brasileiro de Geografia e Estatística.

URL: Disponivel em: <http://www.ibge.gov.br/home/estatistica/indicadores/trabalhoerendimento/pme_nova/princ_carac_trab_dom.pdf $>$. Acesso em: Abril de 2012

IBGE (2012a), Pesquisa de orçamento familiar, Technical report, Instituto Brasileiro de Geografia e Estatística.

URL: Disponivel em: <http://ibge.gov.br/home/download/estatistica.shtm>. Acesso em: Abril de 2012 
IBGE (2012b), Pesquisa mensal do emprego, Technical report, Instituto Brasileiro de Geografia e Estatística.

URL: Disponivel em: <http://ibge.gov.br/home/download/estatistica.shtm>. Acesso em: Abril de 2012

IBGE (2012c), Sistema de contas nacionais, Technical report, Instituto Brasileiro de Geografia e Estatística.

URL: Disponivel em: <http://ibge.gov.br/home/download/estatistica.shtm>. Acesso em: Abril de 2012

IPEA (2012a), Macroeconômico. pib (preços 2011), Technical report, Instituto de Pesquisa Economia Aplicada.

URL: Disponivel em <http://www.ipeadata.gov.br>. Acesso em: Junho de 2012

IPEA (2012b), Macroeconômico. população ocupada, Technical report, Instituto de Pesquisa Economia Aplicada.

URL: Disponivel em: <http://www.ipeadata.gov.br>. Acesso em: Junho de 2012

Martins, A. (2012), 'Renda que mais cresce é a do empregado doméstico'.

URL: Disponivel em: <http://www.valor.com.br/brasil/2549942/renda-quemais-cresce-e-do-empregado-domestico >. Acesso em: março de 2012

Mattos, M. R. (2009), 'Trabalhadores urbanos e domésticos: a constituição federal e sua assimetria', Revista Estudos Feministas 17(3), 871-878.

Melo, H. P. (1998), 'O trabalho doméstico remunerado no brasil: de criadas a trabalhadoras', Revista Brasileira de Estudos Populacionais 15(1), 125-132.

Organização Internacional do Trabalho (2011a), Global and regional estimates on domestic workers, Policy brief (4).

Organização Internacional do Trabalho (2011b), Guia para programas de qualificação para as trabalhadoras domésticas, Programa de promoção da igualdade de gênero e raça no mundo do trabalho.

Organização Internacional do Trabalho (2011c), Remuneration in domestic work, Policy brief (1).

Peter, W. W., Horridge, M., Meguer, G., Navqui, F. \& Parmenter, B. R. (1996), The theoretical structure of monash-mrf, Working Paper OP-9850.

URL: Disponivel em: <http://www.copsmodels.com/ftp/workpapr/op-85.pdf>

Theodoro, M. I. A. \& Scorzafave, L. G. (2011), 'Impacto da redução dos encargos trabalhistas sobre a formalização das empregadas domésticas', Revista Brasileira de Economia 65(1), 93-109.

Tourinho, O. A. F., Kume, H. \& Pedroso, A. C. S. (2007), 'Elasticidades de armington para o brasil: 1986-2002', Revista Brasileira de Economia 61(2), 245267.

Varian, H. R. (1992), Microeconomic Analysis, 3 edn, Norton and Company, New York. 


\section{Apêndice $A \quad O$ modelo BRIDGE ${ }^{15}$}

A operacionalização de um modelo EGC é composta por duas partes. A primeira é a especificação, que consiste em determinar as formas funcionais, baseadas na teoria microeconômica tradicional consolidada. A segunda parte é denominada de calibragem, e consiste na determinação de uma solução inicial. Para a execução dessas duas etapas são necessários dois tipos de dados: os provenientes da matriz de absorção (núcleo da base de dados do modelo), as quais retratam os fluxos da economia, e ainda os parâmetros comportamentais relativos às formas funcionais adotadas (como por exemplo, as elasticidades de exportação, elasticidades de substituição).

A estrutura do núcleo da base de dados do modelo é representada na Figura 5. As linhas mostram a estrutura de compras realizadas por cada agente representado nas colunas. Cada um dos 116 bens identificados pode ser obtido no mercado nacional ou internacional. Os bens são consumidos pelos 60 setores, para investimento, consumo das 10 famílias representativas, consumo do governo, variação de estoques e exportações. Sobre o consumo de bens pelos agentes incidem margens $(m)$ e impostos $(t)$. São utilizados três fatores de primários: terra, trabalho e capital. Sobre a produção dos setores incidem impostos (V1PTX), assim como sobre a folha de salários (V1TAX). A matriz de produção (MAKE) representa a produção dos $c$ bens pelos $i$ setores, e o imposto sobre as importações é representado pelo vetor V0TAR.

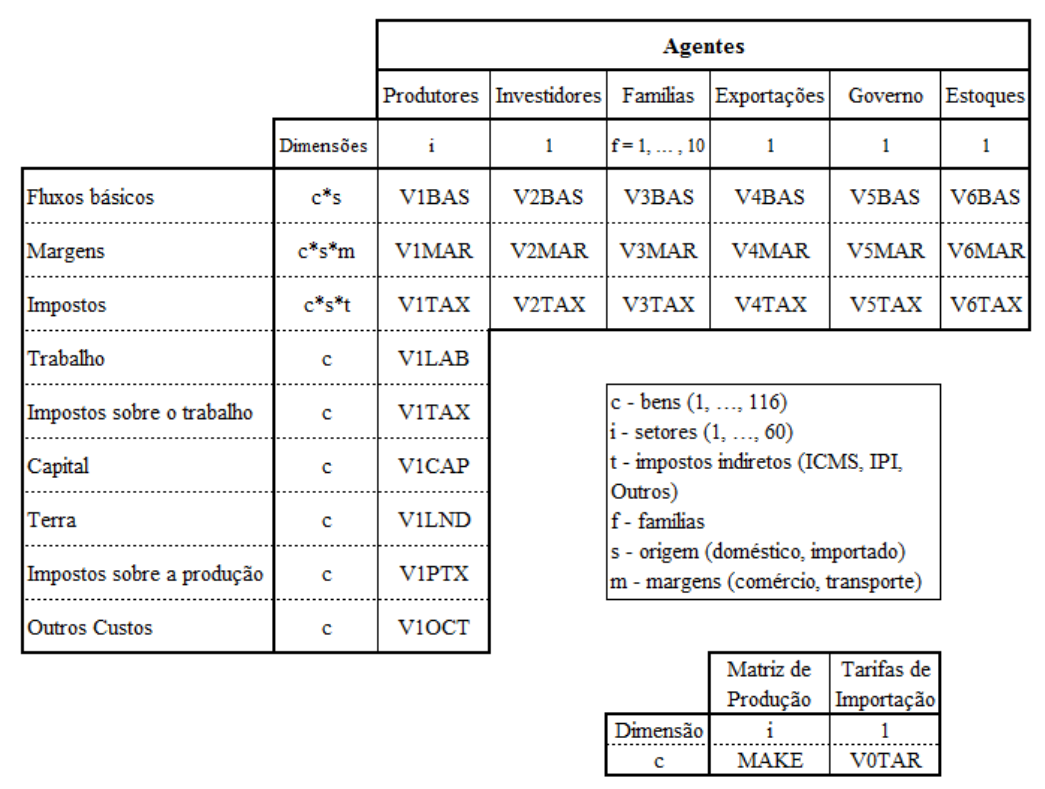

Fonte: Elaboração própria.

Figura A.1: Núcleo da base de dados do modelo EGC

O modelo requer equações de demanda para todos agentes e fluxos representados na economia: demanda por produtos domésticos e importados, de-

\footnotetext{
${ }^{15}$ Esta seção foi desenvolvida no âmbito do Núcleo de Estudos em Modelagem Econômica Aplicada (NEMEA) do CEDEPLAR/UFMG, com a participação de todos os seus integrantes.
} 
manda por fatores de produção, equações de preço dos bens e fatores, equações de equilíbrio de mercado, e equações de agregados econômicos. Além de dados provenientes das matrizes insumo-produto, os modelos de EGC empregam estimativas de elasticidades e parâmetros. Tais valores são extraídos da literatura, o que é justificado pela escassez de dados para a estimação. São utilizados principalmente parâmetros relativos a elasticidades de substituição entre fatores primários, elasticidades de substituição do tipo Armington (entre as variedades domésticas e importadas dos bens) e elasticidade-gasto consumo das famílias.

Muitos desses parâmetros, como a elasticidade de substituição entre fatores primários e a elasticidade de substituição entre bens domésticos e importados, obtidas das estimativas econométricas contidas no Modelo de Equilíbrio Geral Computável Multi-Regional TERM-CEDEPLAR (Domingues \& Faria 2009). A elasticidade de Armington é definida por produto e é idêntica tanto para bens intermediários (SIGMA1), quanto para bens de investimento (SIGMA2) e para a demanda das famílias (SIGMA3). Tais parâmetros foram retirados de Tourinho et al. (2007). Quando necessário, as estimativas foram compatibilizadas aos setores do modelo.

A estrutura de demanda das famílias incorpora também em sua formulação o parâmetro de Frisch Frisch (1959), que é um parâmetro de substituição que mede a sensibilidade da utilidade marginal da renda. ${ }^{16}$ Ele é estimado com um valor negativo e é maior, em módulo, quanto mais pobre for a população em análise. Em outras palavras, quanto maior este parâmetro, em módulo, menor o grau de consumo de "luxo" e maior o grau de consumo de "subsistência". O BRIDGE - TAX emprega o valor - 2, 48, que foi o primeiro a ser estimado para a economia brasileira no modelo TERM-CEDEPLAR. Os resultados apontam uma estimativa de $-2,48$, que coloca o Brasil, de acordo com a definição original (Frisch 1959) no extrato de consumo de renda média (Domingues \& Faria 2009).

Complementando a estrutura de demanda das famílias, utiliza-se um parâmetro que mede a elasticidade gasto dispêndio (EPS) das mesmas. Esses valores foram retirados de Hoffmann (2007). Hoffmann (2007) calcula a elasticidaderenda de diversos tipos de despesas (e.g. alimentação, habitação, vestuário, transporte, dentre outras), utilizando os dados da POF 2002/2003, desagregadas para dez classes de renda familiar per capita. A partir dessas estimativas, as elasticidades-renda foram compatibilizadas aos setores do modelo, obtendo assim, uma matriz de elasticidade gasto por 10 tipos de famílias, distribuídas por decis de renda.

O método de solução do modelo é do tipo Johansen ${ }^{17}$ que parte de um sistema de equações do tipo:

$$
F(V)=0
$$

Onde $V$ é um vetor de equilíbrio de dimensão $n$ (número de variáveis), e $F$ é uma função-vetor não-linear de dimensão $m$ (número de equações). Supõese que $F$ seja diferenciável, e que o número de variáveis seja maior que o número de equações no sistema $(n>m)$. Dessa forma, $(n-m)$ variáveis devem ser determinadas exogenamente. Uma solução inicial de equilíbrio, $V^{*}$, deve ser determinada para fins de calibragem, ou seja, supõe-se que:

\footnotetext{
${ }^{16}$ Para maiores detalhes ver Dixon \& Rimmer (1998).

${ }^{17}$ Maiores detalhes podem ser encontrados em Dixon et al. (1982) e Dixon \& Parmenter (1996).
} 


$$
\exists V=V^{*} \text { talqueF }\left(V^{*}\right)=0
$$

Dada a solução inicial, $V^{*}$, um novo conjunto de soluções pode ser obtido para um dado vetor de alterações nas variáveis exógenas. Dessa forma, para se computar o novo conjunto de soluções para o modelo é necessária a partição do vetor $V$ em dois grupos de variáveis, endógenas e exógenas. Seja $Y$ o vetor contendo as $m$ variáveis endógenas e $X$ o vetor contendo as $(n-m)$ variáveis exógenas. A equação 2 pode ser reescrita como:

$$
F(Y, X)=0
$$

O problema é computar $Y$ para um dado $X$, sendo que não é possível, normalmente, escrever $Y$ como uma função explícita de $X$. Várias técnicas podem ser empregadas para computar $Y$. A solução por linearização assume que já se possui alguma solução para o sistema $\left(Y^{0}, X^{0}\right)$, tal que:

$$
F\left(Y^{0}, X^{0}\right)=0
$$

Em geral a solução inicial é obtida dos dados do período base em que o modelo é calibrado, ou seja, assume-se que o sistema é válido para algum ponto no passado. Para pequenas alterações em $d X$ e $d Y$ e sob hipóteses convencionais para o comportamento da função $F$, a diferenciação total de (3) permite obter: ${ }^{18}$

$$
F_{Y}(Y, X) d Y+F_{X}(Y, X) d X=0
$$

Onde $F_{Y}$ e $F_{X}$ são matrizes de derivadas parciais de $F$ avaliadas em $\left(Y^{0}\right.$, $\left.X^{0}\right)$. Para que as soluções sejam obtidas na forma de taxas de variação é conveniente expressar $d Y$ e $d X$ como pequenas variações percentuais $x$ e $y$. Portanto, um típico elemento dos vetores $x$ e $y$ são definidos como:

$$
y=100 d Y / Y \quad x=100 d X / X
$$

Da mesma forma podem ser definidas as seguintes funções:

$$
G_{Y}(Y, X)=F_{Y}(Y, X) \widehat{Y} \quad G_{X}(Y, X)=F_{X}(Y, X) \widehat{X}
$$

Onde $\widehat{Y}$ e $\widehat{X}$ são matrizes diagonais. Assim o sistema linearizado torna-se:

$$
G_{Y}(Y, X)+G_{X}(Y, X)=0
$$

Soluções para sistemas como (8) podem ser facilmente computadas por meio de técnicas de álgebra linear. Estas representam, entretanto, apenas uma solução acurada para pequenas mudanças em $X$ e $Y$. Caso contrário, erros de linearização podem ocorrer. A aproximação linear, ou em primeira ordem, da solução de (8) é dada por:

$$
y=-G_{Y}(Y, X)^{-1} G_{X}(Y, X) x
$$

A equação 9 leva à solução de Johansen, $Y^{J}$, uma aproximação da solução verdadeira, $Y^{\text {exata }}$. Essa observação leva à ideia de particionar as alterações em

\footnotetext{
${ }^{18}$ As hipóteses usuais são de continuidade e diferenciabilidade de $F$ e solução única. Em geral estas características são atendidas em sistemas walrasianos de equilíbrio geral expressos na forma de equações linearizadas.
} 
$X$ em pequenos passos, e para cada sub-alteração em $X$ usar a aproximação linear para derivar a sub-resposta de $Y$. A partir dos novos valores de $X$ e $Y$ as matrizes de coeficientes $G_{Y}$ e $G_{X}$ são recomputadas e o processo é repetido para cada passo. Esta técnica é conhecida como método de Euler, uma das mais simples opções em técnicas de integração numérica - processo de uso de equações diferenciais para se mover de uma solução para outra.

Para uma aproximação em três passos o erro de linearização é sensivelmente menor, aproximando-se da solução exata. Quanto maior o número de passos, melhor a aproximação. No caso do modelo deste trabalho, um procedimento de cálculo em vários estágios (Johansen/Euler) é utilizado, em que o vetor de choques exógenos é dividido em p partes iguais. Desta forma, podese definir uma sequência de cálculos, de modo que as matrizes $G_{Y}$ e $G_{X}$ sejam reestimadas em cada estágio.

A questão teórica que se coloca diz respeito à maneira em que a solução do modelo converge para a solução "verdadeira" à medida que $p$ cresça e, caso convirja, ao número de estágios (tamanho de $p$ ) necessário para se obter uma solução precisa do modelo. Dixon et al. (1982) demonstram que quando $p$ tender a infinito, o método de vários estágios de Johansen/Euler produzirá uma solução exata do modelo. O modelo de EGC foi operacionalizados no programa GEMPACK. ${ }^{19}$

\footnotetext{
${ }^{19}$ Sobre sua utilização na implementação de modelos EGC ver Harrison \& Pearson (2002).
} 